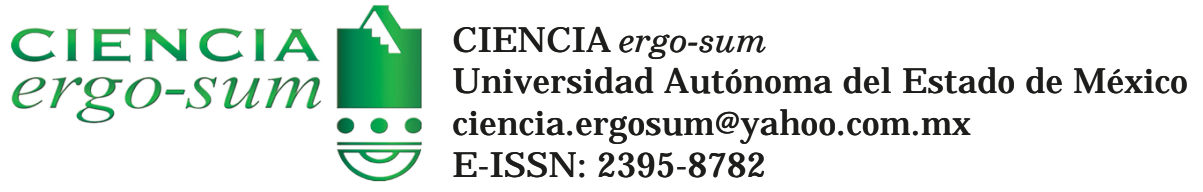

\title{
Evaluación de receptores GPS de bajo costo de alta sensibilidad para trabajos geodésicos. Caso de estudio: línea base geodésica
}

Zamora Maciel, Alejandra; Romero-Andrade, Rosendo; Moraila-Valenzuela, Carlos R.; Pivot, Fredériqué Evaluación de receptores GPS de bajo costo de alta sensibilidad para trabajos geodésicos.

Caso de estudio: línea base geodésica

CIE NCIA ergo-sum, vol. 27, núm. 1, marzo-junio 2020| e73

Universidad Autónoma del Estado de México, México

Esta obra está bajo una Licencia Creative Commons Atribución-N oComercial-SinDerivar 4.0 Internacional.

Zamora Maciel, A., Romero-Andrade, R., Moraila-Valenzuela, C. R. y Pivot, F. (2020). Evaluación de receptores GPS de bajo costo de alta sensibilidad para trabajos geodésicos. Caso de estudio: línea base geodésica. $\mathrm{CI}$ E N CIA ergo-sum, 27(1). https://doi.org/10.30878/ces.v26n2a5 


\title{
Evaluación de receptores GPS de bajo costo de alta sensibilidad para trabajos geodésicos. Caso de estudio: línea base geodésica
}

Evaluation of high-sensitivity low-cost GPS receivers for geodetic applications. Study case: Geodetic baseline

\author{
Alejandra Zamora Maciel \\ Centro de Investigación Cientifica y de Educación \\ Superior de Ensenada, Baja California, México \\ azamora@cicese.edu.mx \\ Rosendo Romero-Andrade \\ Universidad Autónoma de Sinaloa, México \\ r.romero11@info.uas.edu.mx \\ Carlos R. Moraila-Valenzuela \\ Universidad Autónoma de Sinaloa, México \\ c.moraila@uas.edu.mx \\ Fredériqué Pivot \\ Athabasca University, Canada \\ fpivot@athabascau.ca
}

Recepción: 21 de marzo de 2018

Aprobación: 30 de octubre de 2018

\section{Resumen}

Se evalúa una línea base geodésica mediante la implementación de antenas y receptores de bajo costo en sistemas embebidos, así como un receptor geodésico de una frecuencia. Estas mediciones fueron ligadas a una estación de referencia continua de la Red Geodésica Nacional Activa, ubicada en Culiacán, Sinaloa, con el objetivo de determinar la precisión de los equipos de bajo costo estudiados. Para ello se analizan las coordenadas y distancias obtenidas al aplicar el método de posicionamiento diferencial con software académico y comercial. Los resultados presentan diferencias de orden milimétrico entre el posicionamiento con un receptor geodésico y uno de bajo costo para una línea base de $5.1 \mathrm{~km}$ que hacen posible la utilización de equipos de bajo costo en trabajos geodésicos y topográficos.

Palabras Clave: receptor de bajo costo, sistemas embebidos, línea base, DGPS.

\begin{abstract}
Low-cost antennas and receivers were evaluated in embedded systems altogether with a geodetic single-frequency receiver for measure a geodetic baseline; employing this equipment with a continuous reference station of the Red Geodésica Nacional Activa; located in Culiacan, Sinaloa, Mexico.

The aim of this study was determinate the precision of the low-cost receivers employed, evaluating coordinates and distances obtained by applying the differential GPS method with academic and commercial software. Was found millimeter variances between the positioning of a geodetic receiver and the low-cost receivers for a geodetic baseline of 5.1 kilometers, doing possibly the implementation in geodetic or topographic applications.

KEYWORDS: Low-cost receivers, Embedded systems, Geodetic baseline, DGPS.
\end{abstract}

\section{INTRODUCCIÓN}

El Sistema de Posicionamiento Global (GPS por sus siglas en inglés) es de una tecnología que desde su creación se usa ampliamente en diversos ámbitos, ya sea científico, de ingeniería, transportes, etc. Esta tecnología en las geo-ciencias se emplea en estudios de la tectónica de placas (Cabral et al., 2017), glaciología (Negrel et al., 2017), 
comportamiento de la ionosfera (Ren et al., 2016), meteorología (Guerova et al., 2016), por mencionar algunos. Sin embargo, el posicionamiento satelital también es utilizado en aplicaciones donde no es necesaria una alta precisión como navegación (marítima [Bhatti y Humphreys, 2017], terrestre [Liu et al., 2016] y aérea [BarraganCurrea, 2015]); cuestiones de ingeniería (replanteo [Calina et al., 2015] o construcción [Zhang et al., 2015]), incluso es usado en los teléfonos inteligentes (Korpilo et al., 2017). Los receptores empleados en cuestiones científicas y técnicas son denominados geodésicos con equipos que alcanzan precisiones milimétricas (costando miles de dólares); por otro lado, como alternativa a este tipo de equipos, en los años noventa surgieron receptores denominados de bajo costo o low-cost (Tsakiri et al., 2017) que, aunque más baratos que los receptores geodésicos (apenas cientos de dólares), su precisión variaba en metros, por lo que su uso inició en navegación terrestre.

Actualmente los equipos de bajo costo también son llamados de alta sensibilidad (Schwieger, 2009; Tsakiri et al., 2016), ya que tienen en promedio una sensibilidad de $-160 \mathrm{~dB}$, en contraste a los receptores geodésicos que alcanzan los $-128.5 \mathrm{~dB}$ (Van Digglen, 2009) ocasionando que reciban señales más débiles (degradadas por edificios o que están por salir del área del receptor). Algunas otras cualidades de estos equipos son el bajo consumo de energía, reciben datos en una frecuencia, proporcionan datos de código, poseen fase portadora y su reducido tamaño los hacen altamente portables (Benedetti et al., 2017; Chen et al., 2016).

En los últimos años, receptores y antenas de bajo costo han sido utilizados en diversas aplicaciones alrededor del mundo como agricultura de precisión (Keskin et al., 2017), monitoreo de movimientos tectónicos y detección de zonas inestables (Benoit et al., 2015; Biagi et al., 2015), levantamientos y detección de zonas dañadas en bosques (Rodríguez-Pérez et al., 2007; Tomaštík et al., 2017); también se ha propuesto su uso en unmanned surface vehicles (USV por sus siglas en inglés), donde podrían emplearse para tareas de búsqueda y rescate (Leonard y Bahr, 2016; Matias et al., 2015), en unmannned aerial vehicles (UAV por sus siglas en inglés), conocidos como drones (Huang et al., 2016), así como en estudios de actividad física (Krenn et al., 2011).

Dados los estudios en diversos ámbitos que se han llevado a cabo, así como el aumento de disponibilidad y uso de receptores de bajo costo, uno de los propósitos de este trabajo es determinar el tipo de aplicación topográfica o geodésica donde podrían desempeñarse de manera óptima en términos de precisión para la elaboración de redes geodésicas, propagación de coordenadas y replanteos (Díaz Hernández, 2001), además de ser evaluados según las normas del Instituto Nacional de Estadística y Geografía (INEGI). De tal manera, se presenta una evaluación de dos receptores y una antena de bajo costo tomando como comparación un receptor geodésico de una frecuencia (comúnmente encontrado en obra civil debido a su bajo costo). Para ello, se midió una línea base geodésica (que es un apoyo para levantamientos topográficos) (Díaz Hernández, 2001) aplicando el método GPS diferencial. Los resultados son ligados a la estación de monitoreo continuo CULC de la Red Geodésica Nacional Activa (RGNA) como parte de los lineamientos de las normas técnicas para levantamientos geodésicos que señala el Instituto Nacional de Estadística y Geografía (INEGI, 1998).

\section{Materiales y Métodos}

\section{1. Método de posicionamiento diferencial}

El posicionamiento diferencial con GPS o DGPS es una técnica de posicionamiento en postproceso donde se usan dos o más receptores. Un receptor es colocado en una estación de referencia con coordenadas conocidas y el otro receptor se coloca en el vértice o estación se requiere calcular coordenadas, lo cual se hará en relación con la estación de referencia (Hofmann-Wellenhof et al., 2008). El algoritmo de DGPS se basa en diferencias simples con pseudorangos para una época, para un satélite dado. Al tomar la ecuación de pseudorango:

$$
P=\rho+c(\Delta t-\Delta T)+d_{\text {ion }}+d_{\text {trop }}+M+e
$$


Dónde: $P$ es el pseudorango; $\rho$ es la distancia geométrica al satélite; $c$ la velocidad de la luz; $\Delta t$ y $\Delta T$ es la diferencia del tiempo entre el reloj del satélite y el receptor en tiempo GPS; $d_{\text {ion }} \mathrm{y} d_{\text {trop }}$ son los retardos provocados por la ionósfera y la tropósfera; $M$ es el efecto de la multitrayectoria; $e$ es el ruido del receptor.

La distancia geométrica entre el satélite y el receptor es calculada en función de las coordenadas del satélite $\left(x_{\text {sat }}, y_{\text {sat }}, z_{\text {sat }}\right)$ y del receptor $\left(x_{R x}, y_{R x}, z_{R x}\right)$.

$$
\rho=\sqrt{\left(x_{s a t}-x_{R x}\right)^{2}+\left(y_{s a t}-y_{R x}\right)^{2}+\left(Z_{s a t}-Z_{R x}\right)^{2}}
$$

Posteriormente, se usa una estación de referencia de la cual se conocen sus coordenadas precisas; éstas se representan como $x_{0}, y_{0}$ y $z_{0}$. La distancia de la estación de referencia o base al satélite se calcula como:

$$
R_{0}=\sqrt{\left(x_{s a t}-x_{0}\right)^{2}+\left(y_{s a t}-y_{0}\right)^{2}+\left(Z_{s a t}-Z_{0}\right)^{2}}
$$

\subsection{Línea base geodésica}

Una línea base geodésica es un vector tridimensional entre dos estaciones de las cuales se conocen sus coordenadas. Éstas son empleadas como línea de referencia para trabajos topográficos, geodésicos, redes de triangulación, así como para la calibración de instrumentos electrónicos para medición de distancias (Samad et al., 2016). Al determinar una línea base por medio de GNSS, la obtención de la distancia entre dos estaciones se da por medio del teorema de Pitágoras en una proyección referente a las estaciones:

$$
d=\sqrt{(\Delta \mid x)^{2}+(\Delta \mid y)^{2}}
$$

\subsection{Análisis estadístico simple de las observaciones GPS obtenidas}

El método estadístico descriptivo empleado fue la desviación estándar, la cual es una medida de dispersión que mide el grado de separación de los datos con respecto a un valor central, por lo general es la media aritmética y es usada para evaluar el grado de aceptación de las mediciones (Ghilani, 2010).

$$
s=\sqrt{\frac{\sum_{1=n}^{n}\left(x_{i}-\bar{x}\right)^{2}}{n-1}}
$$

La desviación estándar dice que cualquier medición individual en la muestra tiene $68.3 \%$ de probabilidad de estar dentro de $\pm \sigma$ de la media aritmética de la muestra y un $95.5 \%$ de probabilidad de estar dentro de $\pm 2 \sigma$. Por otro lado, de acuerdo con las normas del Instituto Nacional de Estadística y Geografía, en las normas técnicas de estándares de exactitud posicional se considera la evaluación de la ecuación (5), dentro del círculo de error probable (CEP), a un intervalo de confianza de $95 \%$ :

$$
C E P_{95}=1.2238\left(\sigma_{x}+\sigma_{y}\right)
$$

\section{4. Diseño experimental}

Se realizó una comparación entre receptores de bajo costo y un receptor geodésico de una frecuencia al medir una línea base. El arreglo de los receptores sigue el método GPS diferencial, donde la estación CULC fungirá 
como referencia; por otro lado, la estación a estimar será medida por los receptores de bajo costo y el receptor geodésico de una frecuencia. El estudio fue divido en tres campañas (todas fueron realizadas a la misma hora, pero en diferentes días). En la primera campaña se usó el receptor geodésico de una frecuencia para formar una línea base en conjunto con la estación de referencia CULC, mientras que en las campañas dos y tres se repitieron la línea base con los receptores de bajo costo. Para realizar el postproceso (método GPS diferencial), se emplearon dos software: RTKLIB (Takasu \& Yasuda, 2009), el cual permite manipular los receptores de bajo costo y generar sus archivos RINEX y Leica Geo Office (Leica Geosystems AG, 2017), por ser el fabricante del receptor a utilizar.

\subsection{Metodología de procesamiento}

El proceso de experimentación fue llevado a cabo siguiendo las etapas expuestas en la figura 1. En primera instancia se realizaron tres campañas de medición en diferentes días con diferentes equipos con la finalidad de establecer tres líneas bases geodésicas y compararlas en cuanto a sus coordenadas y distancias obtenidas.

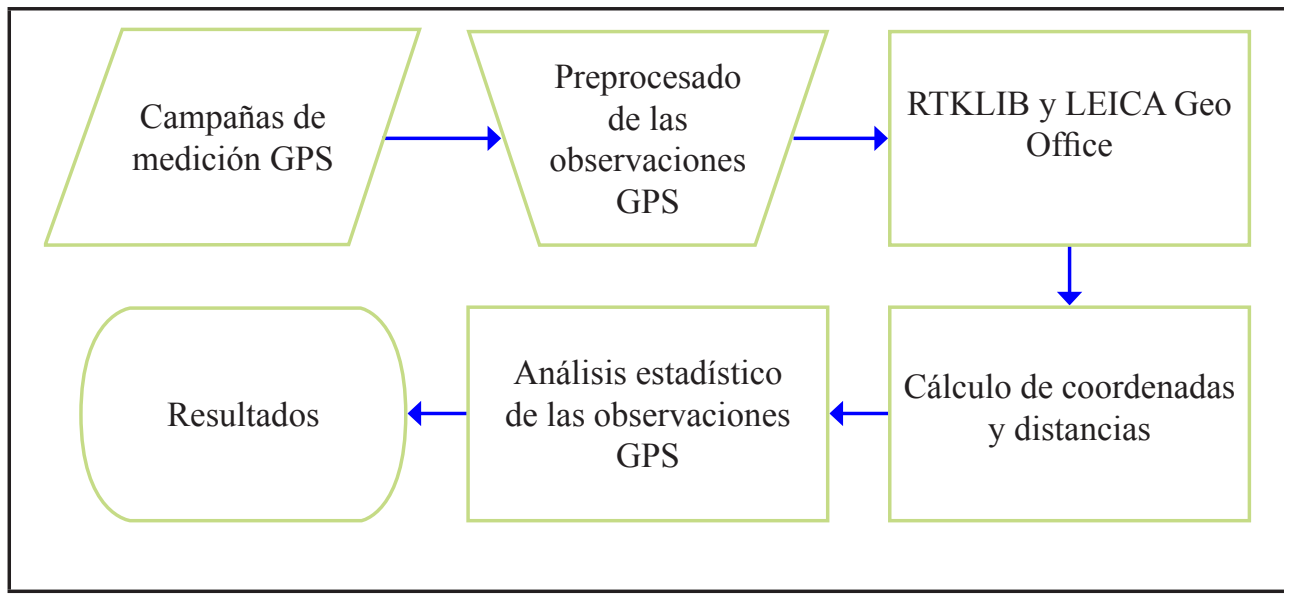

FIGURA 1

Metodología propuesta para el análisis de las observaciones GPS Fuente: elaboración propia.

Una vez obtenidas las observaciones, se llevó a cabo el preprocesamiento de las observaciones GNSS. La edición de los archivos RINEX de los receptores de bajo costo, la estación de referencia CULC y el receptor comercial se realizó con TEQC (Estey y Wier, 2014); se estandarizó el intervalo de observación a 15 segundos, la eliminación de satélites con ruido y la edición de señales recibidas conservando únicamente la señal GPS (dado que no es uniforme en los tres receptores). Una vez tratados los archivos RINEX, se realizó el postprocesamiento de los datos adquiridos obteniendo coordenadas y distancias para la línea base para después ser evaluadas estadísticamente con el fin de determinar la precisión de la medición, siendo procesadas con RTKLIB y Leica Geo Office.

Las configuraciones para los equipos fue llevada a cabo buscando la uniformidad en cada uno de ellos con el fin de evaluar los resultados obtenidos de las observaciones con las mínimas diferencias posibles. Para conseguirlo se consideró el Sistema GPS, una máscara de elevación de $15^{\circ}$ (valores típicos para la máscara de elevación son $10^{\circ}$ y $15^{\circ}$ ), ya que a un ángulo menor los efectos de la troposfera en la señal se tornan más severos, además la visibilidad de los satélites se reduce (Leick et al., 2015), efemérides transmitidas en el mensaje de navegación de la estación de referencia, modelo troposférico de Klobuchar (Klobuchar, 1987) y una corrección ionosférica con el modelo de Saastamoinen (Saastamoinen, 1972). 


\section{RECEPTORES GPS}

\section{1. Receptores GPS de bajo costo}

Se emplearon los receptores de bajo costo de alta sensibilidad (acorde con los datos del fabricante) NS-RAW (sensibilidad de inicio frío es de $-148 \mathrm{~dB}$ y de seguimiento es $-165 \mathrm{~dB}$ ) y NVS08CSM (sensibilidad de inicio frío es de $-143 \mathrm{~dB}$ y de seguimiento es $-160 \mathrm{~dB}$ ) (figura $2 \mathrm{a}$ y $2 \mathrm{~b}$ ), los cuales funcionan en conjunto con la antena Tallysman TW4721 (figura 3), y se comunican con Raspberry Pi (figura 4) por medio de USB; el módulo wifi de Raspberry Pi habilita el acceso a redes inalámbricas permitiendo el control desde un teléfono inteligente o tablet. Todo el sistema funciona con una batería portátil o power bank de $4000 \mathrm{mAh}$ con una entrada y salida de 5v cc 1A.

Los receptores fueron colocados sobre la misma estación de prueba (figura 5) y manipulados con RTKLIB a través de Raspberry Pi; su tarea fue llevar a cabo el monitoreo de las observaciones y el almacenamiento de los datos.

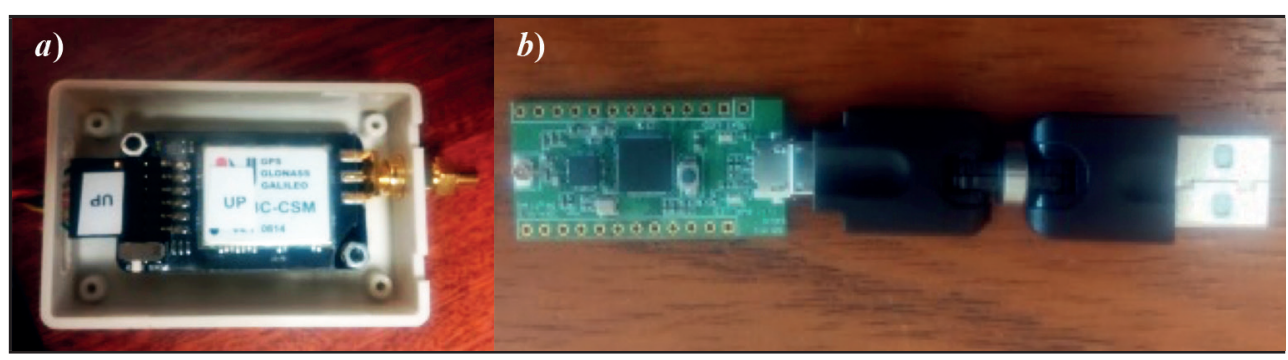

FIGURA 2

Receptores de bajo costo.

Fuente: elaboración propia.

Nota: a): Receptor NVS08CSM. $b$ ): Receptor NS-RAW.

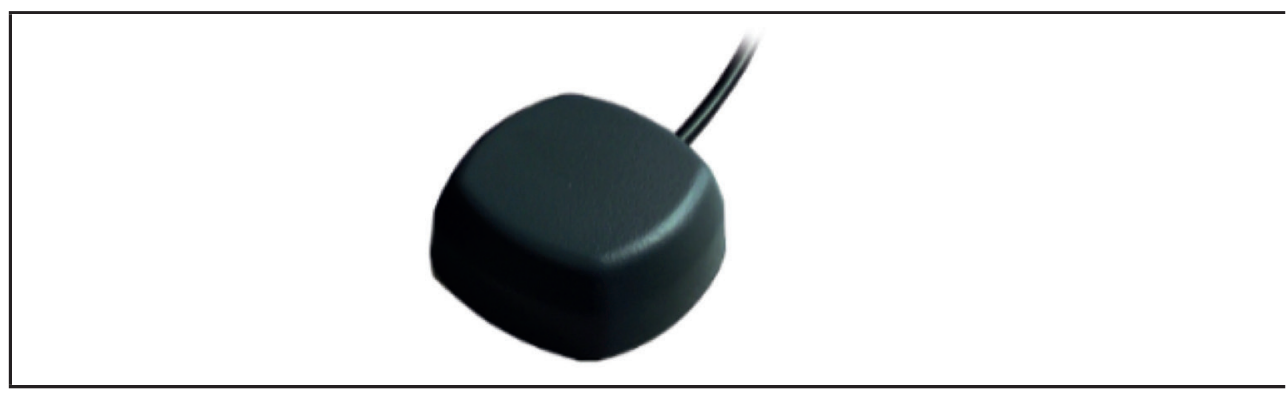

FIGURA 3

Antena Tallysman TW4721

Fuente: Tallysman TW4721, 2017.

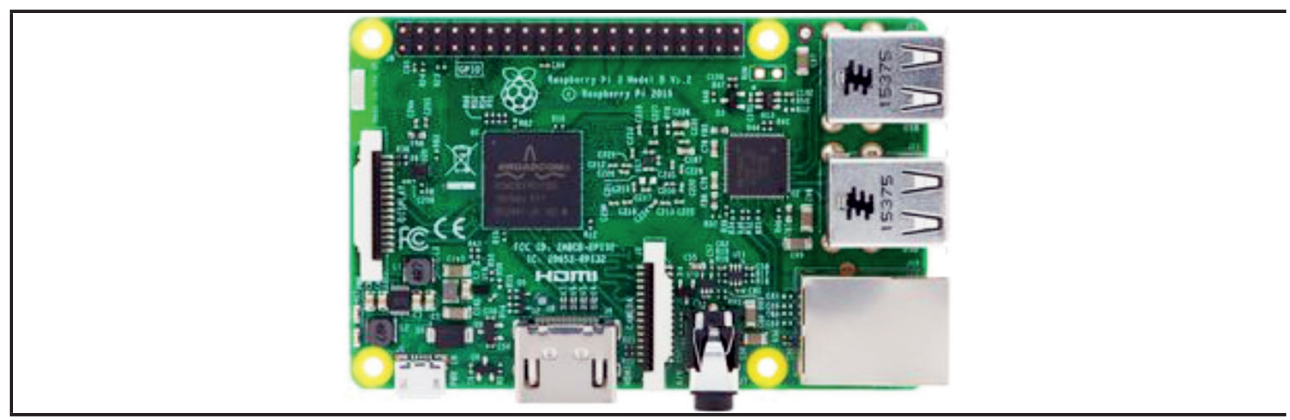

FIGURA 4

Raspberry Pi modelo B

Fuente: Adafruit, 2017. 


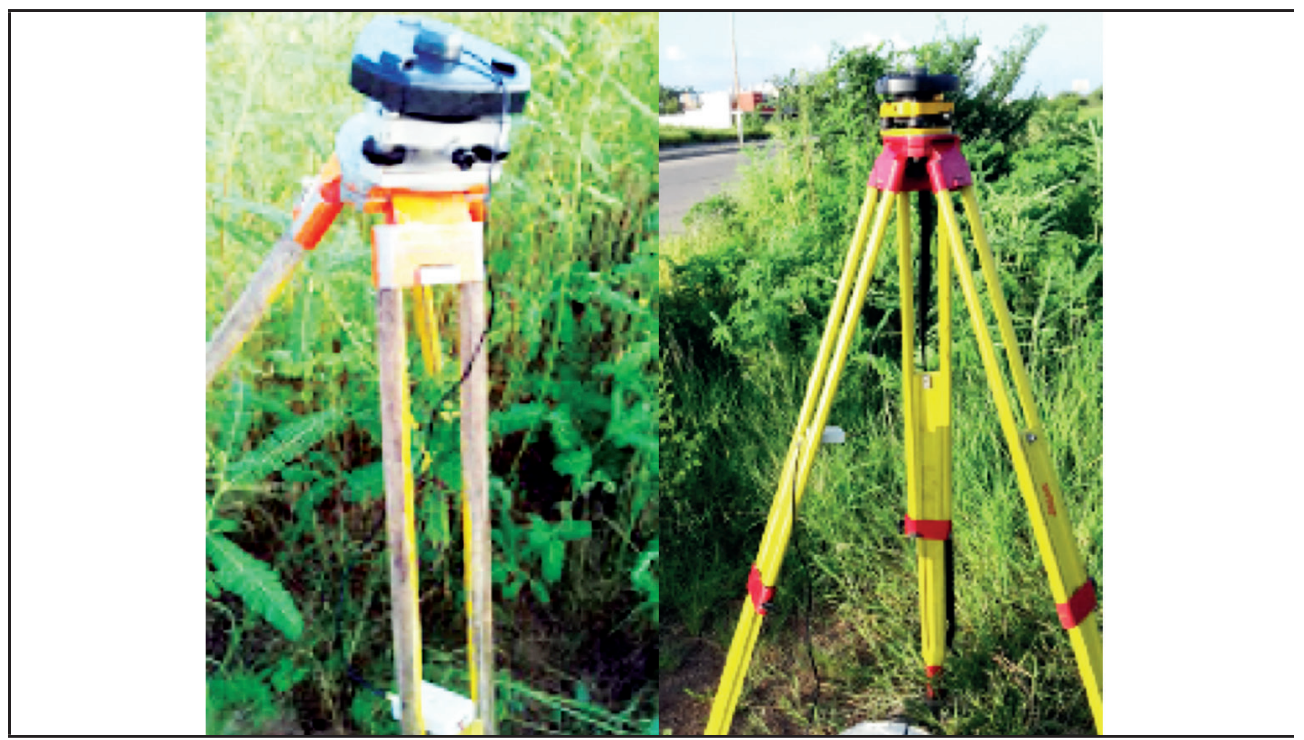

FIGURA 5

Receptores de bajo costo durante la etapa de medición Fuente: elaboración propia.

\section{2. Receptor geodésico}

Se utilizó como receptor de una frecuencia el equipo Leica SR20 (figura 6), el cual cuenta con 12 canales y su precisión en postproceso usando mediciones de código y fase llega a ser de 5 a $10 \mathrm{~mm}+/-2$ ppm (Leica Geosystems AG, 2006). Se programaron sesiones de medición de una hora con una máscara de elevación de $15^{\circ}$ (considerando lo descrito).

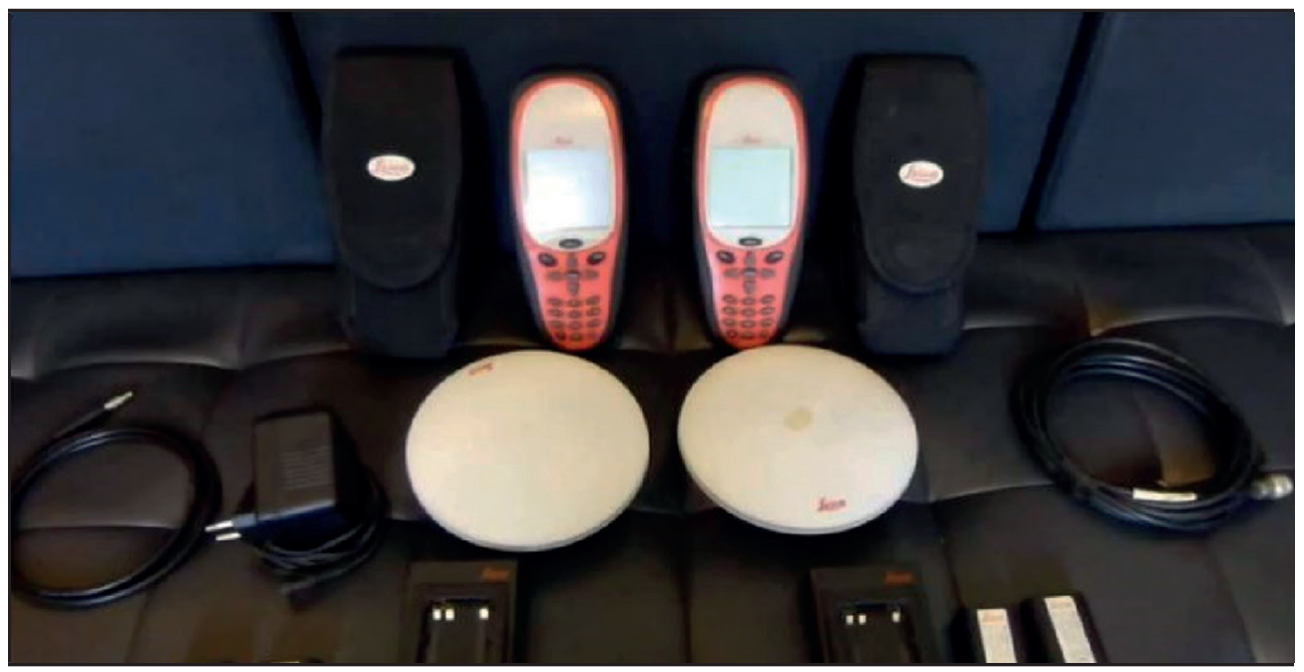

FIGURA 6

Receptor geodésico de una frecuencia Leica SR20

Fuente: Leica Geosystems AG, 2006.

\section{Estación de referencia CULC}

La estación CULC (figura 7) forma parte de las 30 estaciones que conforman la Red Geodésica Nacional Activa (RGNA) del Instituto Nacional de Estadística y Geografía (INEGI), las cuales se encuentran distribuidas por 
todo el país proporcionando monitoreo continuo de datos del Sistema de Navegación Global por Satélite (GNSS por sus siglas en inglés). La estación CULC se compone de un receptor Leica GR10 y una antena Leica AR10; este receptor recibe señales GPS, GLONASS, Galileo, BeiDou y QZSS. La estación de referencia se encuentra sobre la azotea del edificio del INEGI, en Culiacán, Sinaloa (INEGI, 2017).

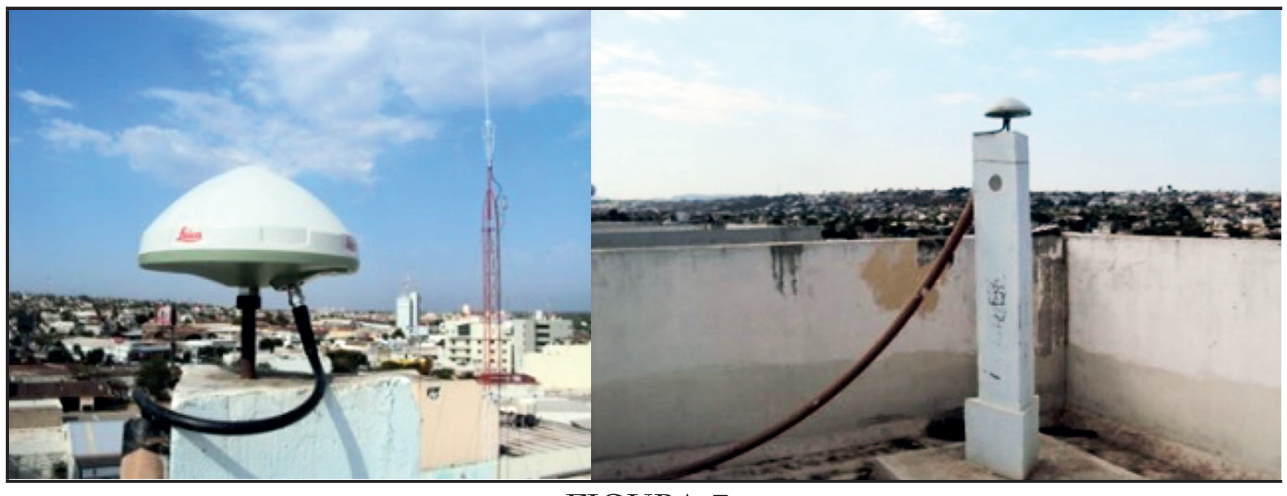

FIGURA 7

Estación de referencia CULC perteneciente a la RGNA Fuente: INEGI, 2017.

\section{1. Área de estudio}

El área de estudio se encuentra en la ciudad de Culiacán, capital del estado de Sinaloa, al noroeste de México. Sus coordenadas son $24^{\circ} 48^{\prime} 15^{\prime \prime} \mathrm{N}$ y $107^{\circ} 25^{\prime} 53^{\prime \prime}$ O y se sitúa a 54 msnm (mapa 1 ).

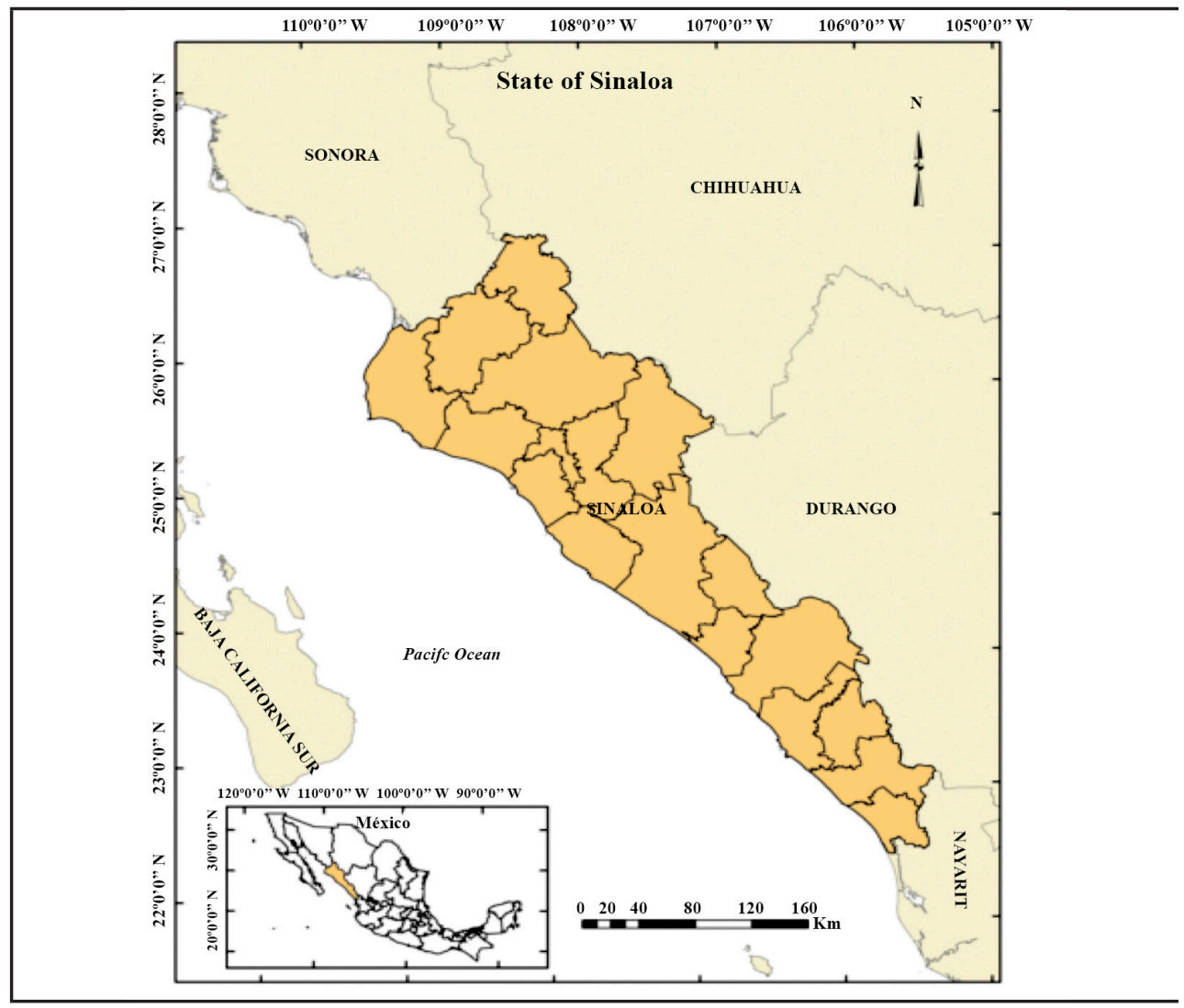

MAPA 1

Ubicación geográfica del estado de Sinaloa

Fuente: Monjardin et al., 2016. 
La experimentación se llevó a cabo en el sector Isla Musala (mapa 2), al noroeste de la ciudad de Culiacán. La estación de prueba fue colocada en esta zona, ya que representa un área sin urbanización y sin vías de tránsito que atraviesen el área de experimentación; además, la distancia en línea recta a la estación de referencia CULC (mapa 3) es de aproximadamente $5.1 \mathrm{~km}$ que de acuerdo con el método de posicionamiento diferencial se recomiendan distancias igual o menores a $10 \mathrm{~km}$ (Takasu y Yasuda, 2013).

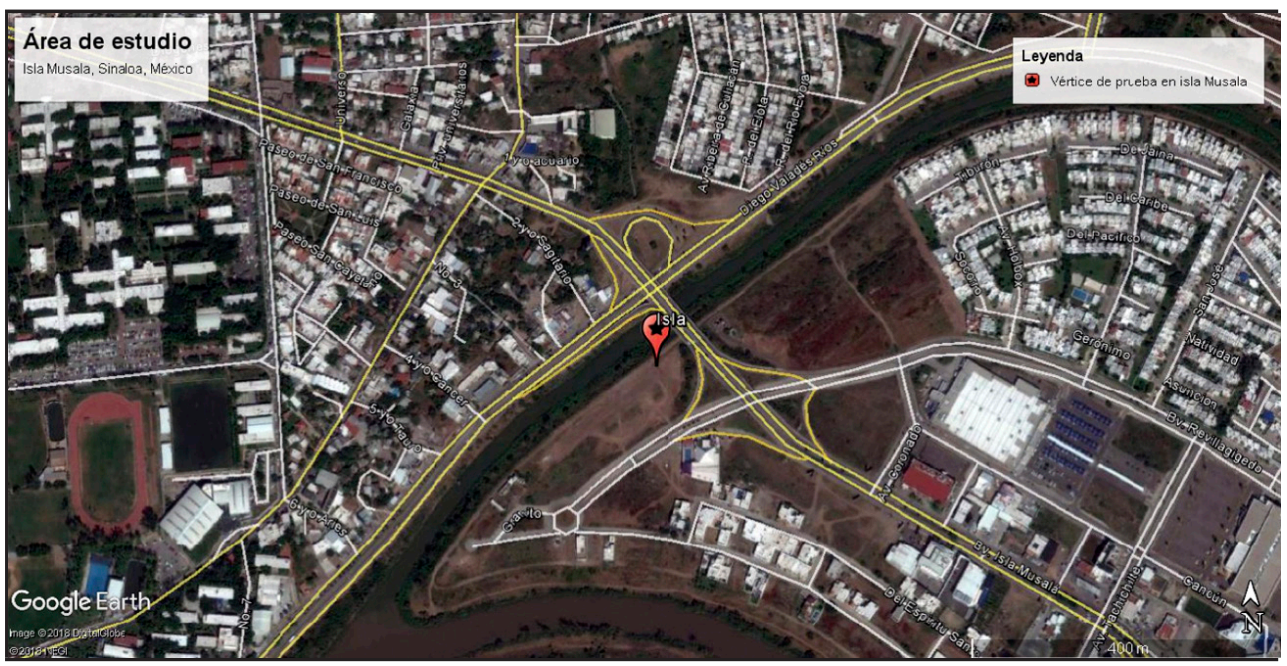

MAPA 2

Área de estudio, Isla Musala, Culiacán, México Fuente: tomada de Google Maps.

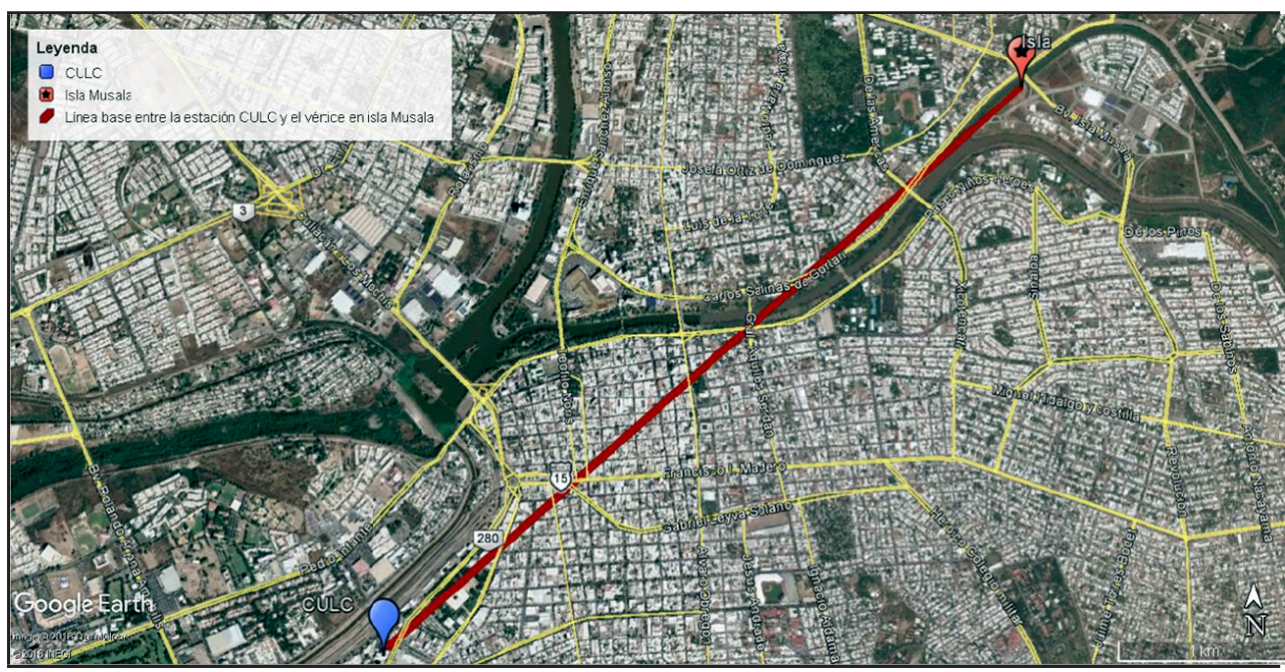

MAPA 3

Línea base entre la estación de prueba en Isla Musala y la estación de referencia

CULC de la RGNA

Fuente: tomada de Google Maps.

\section{Resultados}

Como resultado de las campañas de medición, se observó que es posible implementar los receptores de bajo costo en trabajos topográficos referentes al plano horizontal y descartar el plano vertical dado los resultados obtenidos. Las observaciones GPS se evaluaron mediante las desviaciones estándar, coordenadas y las distancias calculadas, las cuales fueron contrastadas con un receptor geodésico de una frecuencia (considerando este como punto de partida). 
Las coordenadas calculadas a partir de las observaciones GPS se llevaron a cabo mediante el software RTKLIB para ambos receptores de bajo costo en una proyección Universal Transversa de Mercator (UTM), zona 13 Norte. En lo referente al receptor NVS08CSM, los resultados muestran una diferencia de $\cong 3 \mathrm{~cm}$ para las componentes Norte y Este, donde destaca una variación máxima de $\cong 14 \mathrm{~cm}$ para la componente Altura (cuadro 1, gráfica 1). Al igual que para el receptor NSRAW, las diferencias son consistentes en las componentes horizontales y no existe discrepancia significativa en cuanto al receptor NVS08CSM; de acuerdo con Andrei (2012), este comportamiento puede deberse a la resolución de las ambigüedades, lo cual se estima que genera hasta $15 \mathrm{~cm}$ de inestabilidad en el posicionamiento.

\section{CUADRO 1}

Coordenadas Norte, Este y Altura obtenidas con el software RTKLIB, así como la diferencia entre el receptor geodésico (valor real) y los receptores de bajo costo para cada coordenada calculada mediante DGPS

\begin{tabular}{|lrrrrc|}
\hline & $\begin{array}{c}\text { Receptor } \\
\text { geodésico }\end{array}$ & \multicolumn{2}{c}{ Receptores de bajo costo } & $\begin{array}{c}\text { Diferencias entre coordenadas (m) } \\
\text { (geodésico-bajo costo) }\end{array}$ \\
\hline Este & Leica SR20 & \multicolumn{1}{c}{ NS-RAW } & NVS08CSM & 'SR20-NSRAW' & 'SR20-NVS08CSM' \\
Norte & 260003.029 & 260002.991 & 260002.992 & 0.038 & 0.037 \\
Altura & 2747728.642 & 2747728.642 & 2747728.643 & 0.000 & 0.001 \\
\hline
\end{tabular}

Fuente: elaboración propia.

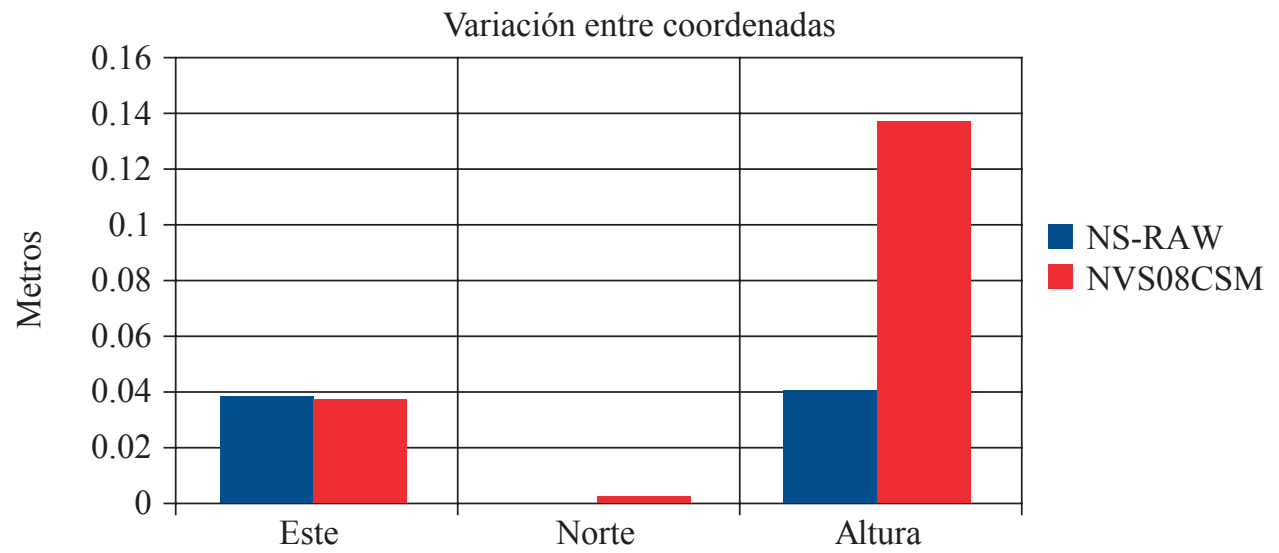

GRÁFICA 1

Diferencia absoluta en metros de las coordenadas obtenidas procesadas con el software RTKLIB considerando como valor real las coordenadas del receptor geodésico de una frecuencia

Fuente: elaboración propia.

Nota: Azul: diferencia entre el receptor Leica SR20 y el receptor de bajo costo NSRAW. Rojo: diferencia entre el receptor Leica SR20 y el receptor de bajo costo NVS08CSM.

Comúnmente en trabajos topográficos, y como ya se ha mencionado, el software Leica Geo Office es utilizado con frecuencia para dar solución a problemas de topografía-geodesia (descartando los trabajos para deformaciones corticales y con fines geofísicos). Al dar solución a las mismas observaciones mediante el software Leica Geo Office (cuadro 2), se encontraron diferencias menores respecto al software RTKLIB; sin embargo, la componente vertical continuó siendo la más afectada. Las variaciones entre dichas soluciones alcanza el orden de $1 \mathrm{~cm}$ para la componente horizontal (gráfica 2) y $2 \mathrm{~m}$ para la componente vertical (gráfica 3). Esta diferencia entre los resultados entre ambos software es debido a la falta de los parámetros de calibración de las antenas de bajo costo (siendo altamente sensibles al efecto multitrayectoria), que evidentemente es considerado por ambos software; sin embargo, para la estación de referencia CULC y para la antena Leica SR20 estos parámetros fueron considerados en ambos programas, lo cual afirma que es la vertical la más afectada para los receptores de bajo costo. 


\section{CUADRO 2}

Coordenadas Norte, Este y Altura obtenidas con el software Leica Geo Office, así como la diferencia entre el receptor geodésico (valor real) y los receptores de bajo costo para cada coordenada calculada mediante DGPS.

\begin{tabular}{|lrrrrr|}
\hline & \multicolumn{2}{c}{$\begin{array}{c}\text { Receptor } \\
\text { geodésico }\end{array}$} & \multicolumn{2}{c}{ Receptores de bajo costo } & \multicolumn{2}{c|}{$\begin{array}{c}\text { Diferencias entre coordenadas (m) } \\
\text { (geodésico-bajo costo) }\end{array}$} \\
\hline Este & Leica SR20 & \multicolumn{1}{c}{ NS-RAW } & NVS08CSM & 'SR20-NSRAW' & 'SR20-NVS08CSM' \\
Norte & 260002.986 & 260002.988 & 260002.996 & 0.002 & 0.010 \\
Altura & 274728.638 & 2747728.671 & 2747728.651 & 0.032 & 0.012 \\
& 10.398 & 12.455 & 12.185 & 2.058 & 1.788 \\
\hline
\end{tabular}

Fuente: elaboración propia.

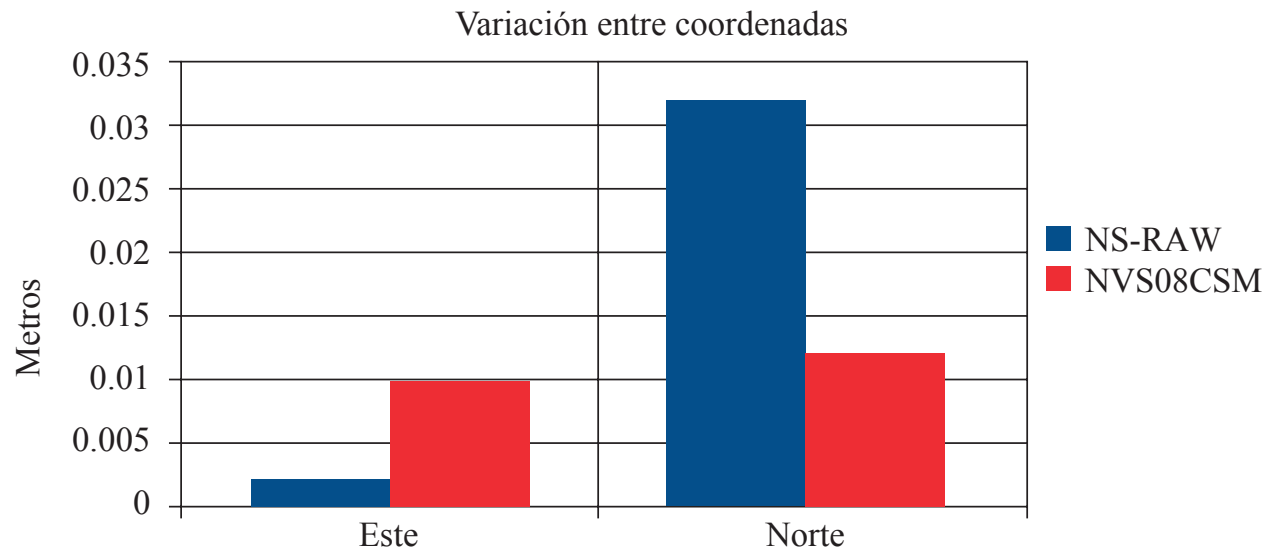

GRÁFICA 2

Diferencia absoluta en metros de las coordenadas obtenidas procesadas el software Leica Geo Office considerando como valor real las coordenadas del receptor geodésico de una frecuencia

Fuente: elaboración propia.

Nota: Azul: receptor Leica SR20 menos receptor de bajo costo NSRAW. Rojo: Receptor Leica SR20 menos el receptor de bajo costo.

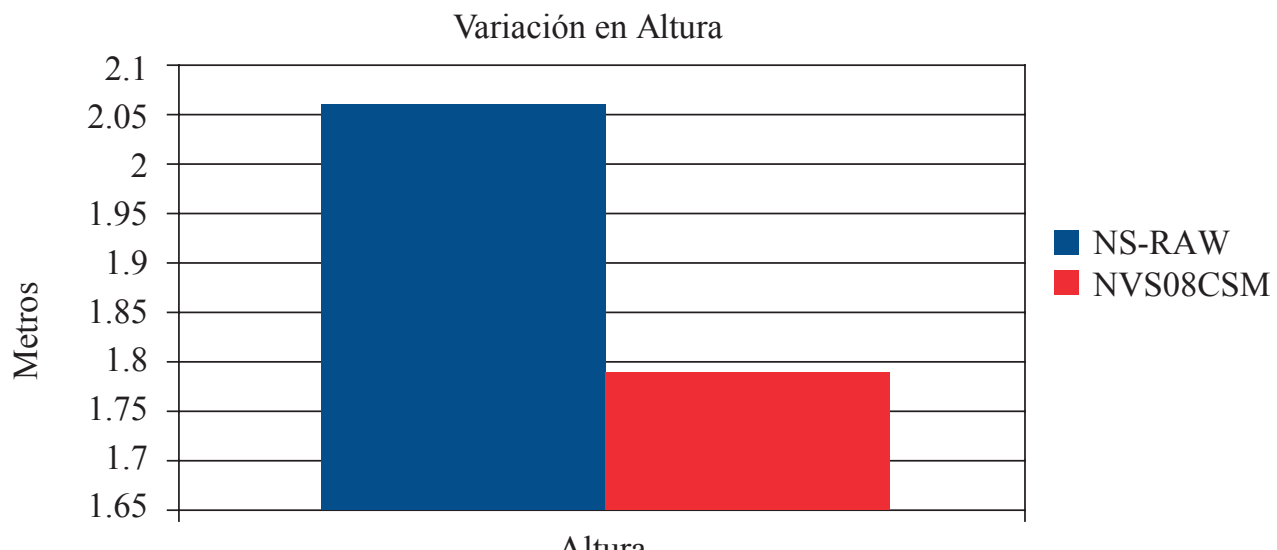

Altura

GRÁFICA 3

Diferencia absoluta de la componente vertical obtenida con el software Leica Geo Office considerando como valor real las coordenadas del receptor geodésico de una banda

Fuente: elaboración propia.

Nota: Azul: receptor Leica SR20 menos receptor de bajo costo NS-RAW. Rojo: Receptor Leica SR20 menos el receptor de bajo costo NVS08CSM. 
Otro cálculo referente a una línea base geodésica es la distancia, la cual es estimada entre ambos receptores. Como producto de la obtención de coordenadas, se calcularon las distancias de la línea base geodésica (CULC-Isla Musala) a partir de los resultados del software RTKLIB y Leica Geo Office. Las diferencias entre las distancias calculadas con las coordenadas obtenidas con el software RTKLIB se encuentran en el orden de los $3 \mathrm{~cm}$ entre los receptores de bajo costo (cuadro 3 y gráfica 4) en una distancia de 5.122 $\mathrm{km}$ de la estación por estimar a la de referencia continua. En comparación con las distancias y diferencias obtenidas al calcular con el software Leica Geo Office (cuadro 4 y gráfica 5) existe una disminución en las discrepancias entre las distancias que se aproximan al centímetro, lo cual hace referencia a que las coordenadas provenientes de los cálculos con el software Leica Geo Office son precisas en consideración de las obtenidas con el software RTKLIB debido al manejo de los modelos y parámetros; la técnica diferencial es una debilidad misma en el software.

\section{CUADRO 3}

Distancias calculadas a partir de las coordenadas obtenidas con el software RTKLIB considerando como distancia real la estimada con el receptor Leica SR20

\begin{tabular}{|llc|}
\hline \multicolumn{1}{|c}{ Receptor } & $\begin{array}{l}\text { Distancia (m) } \\
\text { CULC-ISLA }\end{array}$ & Diferencia entre distancias (m) \\
\hline SR20 & 5122.522 & \\
NS-RAW & 5122.493 & $0.029 \mathrm{~m}$ \\
NVS08CSM & 5122.490 & $0.032 \mathrm{~m}$ \\
\hline
\end{tabular}

Fuente: elaboración propia.

Nota: Diferencias entre distancias: discrepancia de la distancia obtenida del receptor Leica SR20 y receptores de bajo costo.

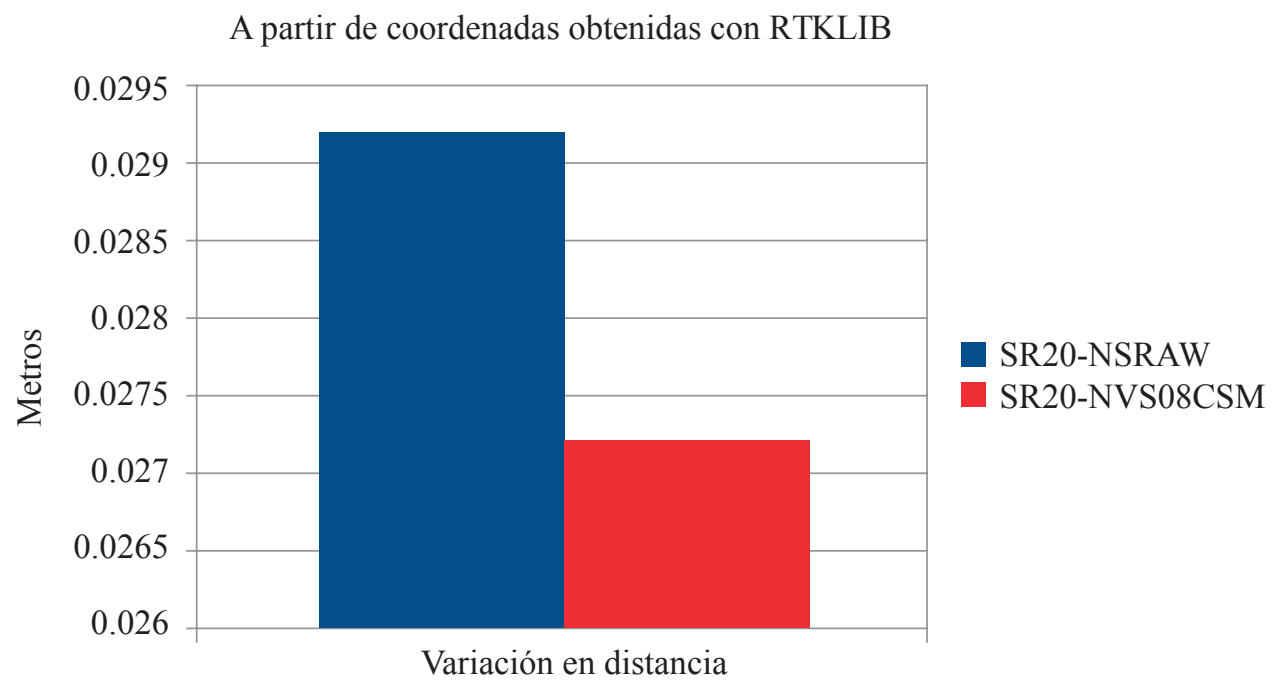

GRÁFICA 4

Diferencia entre la distancia calculada del receptor de una frecuencia y los de bajo costo con el software RTKLIB considerando como distancia real la distancia obtenida con el receptor Leica SR20.

Fuente: elaboración propia.

Nota: Azul: diferencias entre distancias calculadas en metros del receptor Leica SR20 y el receptor de bajo costo NSRAW. Rojo: Azul: diferencias entre distancias calculadas en metros del receptor Leica SR20 y el receptor de bajo costo NVS08CSM. 


\section{CUADRO 4}

Distancias calculadas a partir de las coordenadas obtenidas con el software Leica Geo Office considerado como distancia real la estimada con el receptor Leica SR20

\begin{tabular}{|lcc|}
\hline \multicolumn{1}{|c|}{ Receptor } & Distancia $(\mathbf{m})$ CULC-ISLA & Diferencia entre distancias $(\mathbf{m})$ \\
\hline SR20 & 5122.775 & \\
NS-RAW & 5122.759 & 0.0158 \\
NVS08CSM & 5122.753 & 0.0080 \\
\hline
\end{tabular}

Fuente: elaboración propia.

Nota: Diferencias entre distancias: discrepancia de la distancia obtenida del receptor Leica SR20 y receptores de bajo costo.

A partir de coordenadas obtenidas con LEICA Geo Office

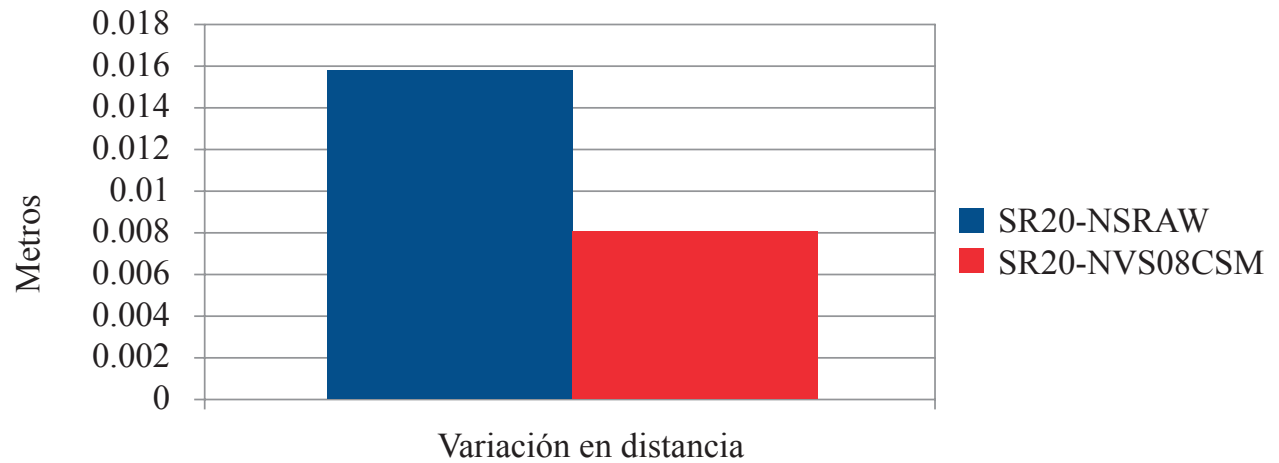

\section{GRÁFICA 5}

Diferencia entre la distancia calculada del receptor de una frecuencia y los de bajo costo con el software Leica Geo Office considerando como distancia real la distancia obtenida con el receptor Leica SR20

Fuente: elaboración propia.

Nota: Azul: diferencias entre distancias calculadas en metros del receptor Leica SR20 y el receptor de bajo costo NSRAW. Rojo: diferencias entre distancias calculadas en metros del receptor Leica SR20 y el receptor de bajo costo NVS08CSM.

Como último parámetro de evaluación, se describió la desviación estándar de las mediciones obtenidas como resultado del procesamiento. En el cuadro 5, gráficas 6 y 7 se presentan las desviaciones estándar que resultaron del postprocesamiento con una precisión en el orden de décimas de milímetros en la componente horizontal. Sin embargo, para el caso de la vertical, sigue siendo considerablemente de menor precisión para los receptores de bajo costo al ser comparados con un receptor de una frecuencia. Esto está relacionado con lo descrito: dado que es sensible al efecto multitrayectoria y parámetros de antena, dificulta la estimación de la altura; los resultados muestran que en ambos software la componente vertical para el caso de los receptores de bajo costo es la de menor precisión.

CUADRO 5

Desviaciones estándar de las coordenadas obtenidas en el software RTKLIB y Leica Geo Office

\begin{tabular}{|lccc|ccccc}
\hline \multicolumn{3}{c}{ RTKLIB } \\
Receptor & $\sigma_{x}$ & $\sigma_{y}$ & $\sigma_{z}$ & Receptor & $\sigma_{x}$ & $\sigma_{y}$ & $\sigma_{z}$ \\
\hline SR20 & 0.0005 & 0.0004 & 0.0011 & SR20 & 0.0008 & 0.0004 & 0.0007 \\
NS-RAW & 0.0042 & 0.0026 & 0.0170 & NS-RAW & 0.0017 & 0.0019 & 0.0045 \\
NVS08CSM & 0.0020 & 0.0011 & 0.0041 & NVS08CSM & 0.0003 & 0.0003 & 0.0007 \\
\hline
\end{tabular}

Fuente: elaboración propia. 


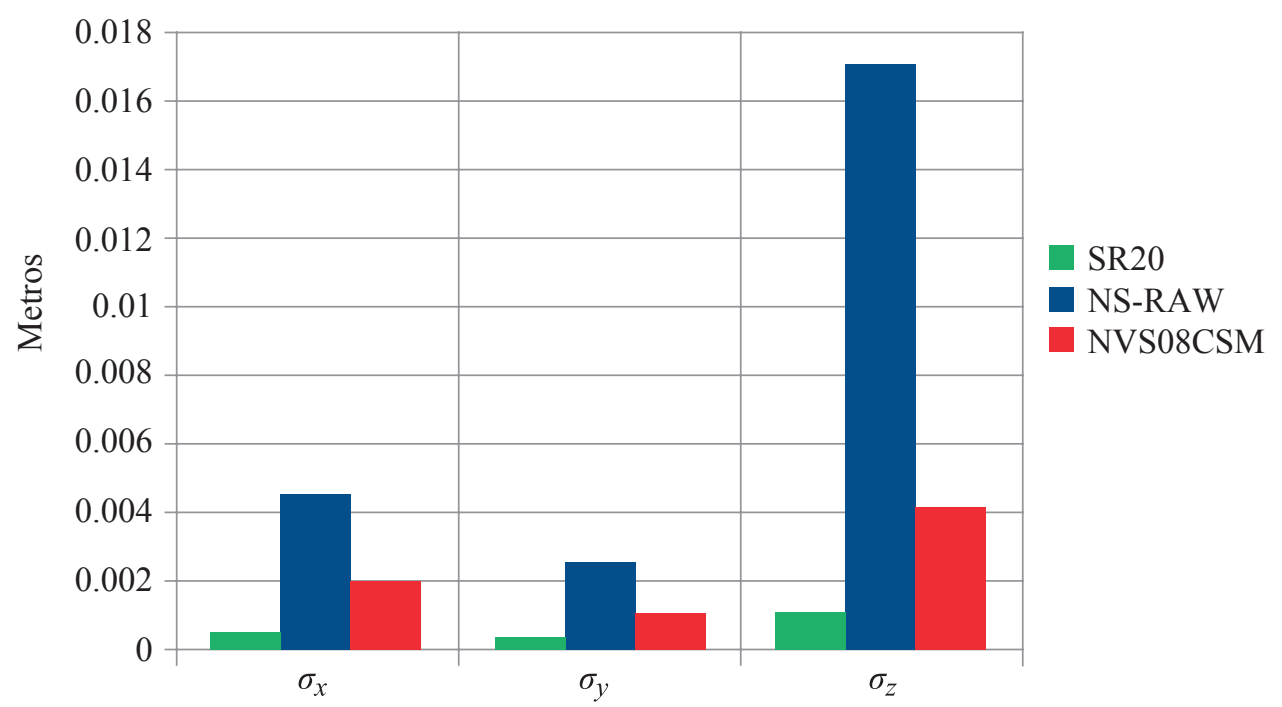

GRÁFICA 6

Desviaciones estándar calculadas para las coordenadas obtenidas a partir del software RTKLIB

Fuente: elaboración propia.

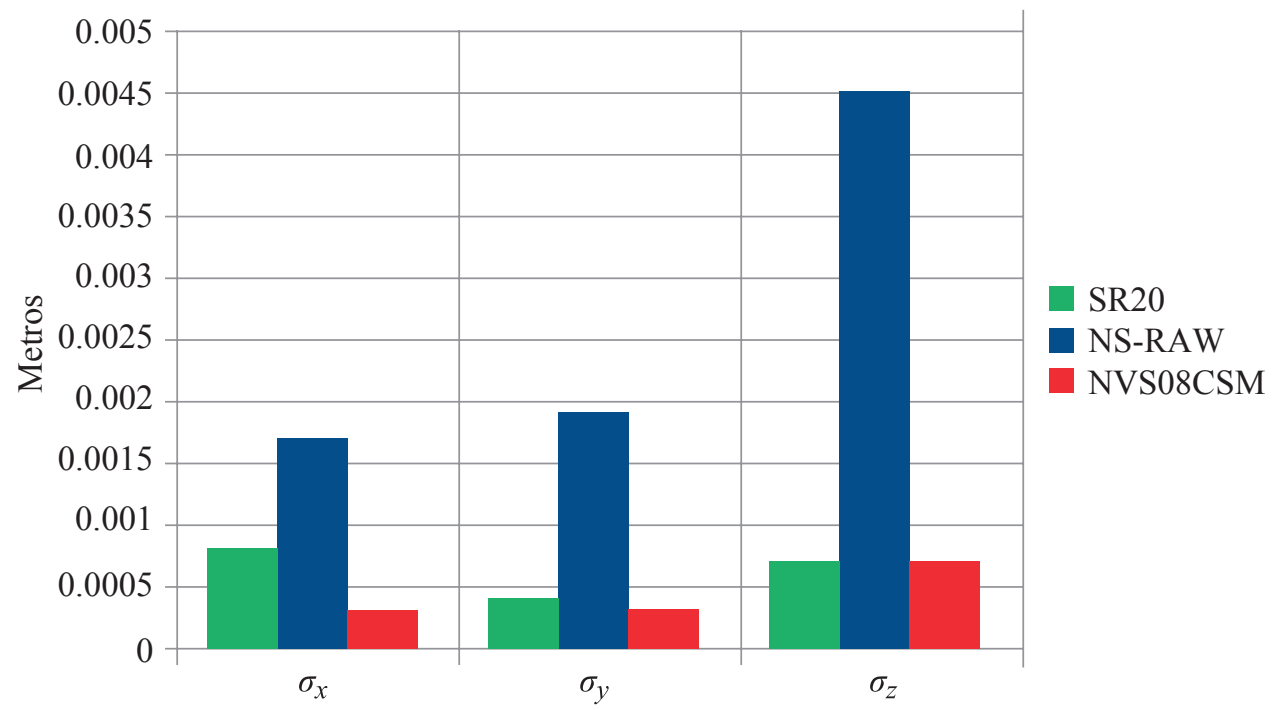

GRÁFICA 7

Desviaciones estándar calculadas para las coordenadas obtenidas a partir del software Leica Geo Office Fuente: elaboración propia.

Conforme a las normas técnicas de los estándares de exactitud posicional (INEGI, 2010), se evaluaron las posiciones calculadas (cuadro 6), las cuales son aptas para trabajos geodésicos horizontales, en específico para levantamientos topográficos-geodésicos (de acuerdo con lo expuesto por el artículo 9); no obstante, en lo que respecta a la componente vertical no es posible evaluar, ya que no fue ligado a una red de nivelación primaria como marca la norma. 


\section{CUADRO 6}

Cálculo del círculo de error probable conforme a las normas técnicas expuestas por INEGI

\begin{tabular}{|lccclccc}
\multicolumn{3}{c}{ RTKLIB } & \multicolumn{5}{c}{ Leica Geo Office } \\
Receptor & $\sigma_{x}$ & $\sigma_{y}$ & $C E P_{95}$ & Receptor & $\sigma_{x}$ & $\sigma_{y}$ & $C E P_{95}$ \\
SR20 & 0.0005 & 0.0004 & 0.003 & SR20 & 0.0008 & 0.0004 & 0.003 \\
NS-RAW & 0.0042 & 0.0026 & 0.010 & NS-RAW & 0.0017 & 0.0019 & 0.005 \\
NVS08CSM & 0.0020 & 0.0011 & 0.004 & NVS08CSM & 0.0003 & 0.0003 & 0.001 \\
\hline
\end{tabular}

Fuente: elaboración propia.

\section{Discusión}

Se presentó el análisis de una línea base geodésica por medio de la implementación de receptores GPS de bajo costo y un receptor GPS de una frecuencia. La experimentación se diseñó con base en la ley del Instituto de Información Territorial (IIEG, 2011), artículo 6, fracción IX del sistema de información territorial, la cual especifica que para la distancia a una estación GPS $(<100 \mathrm{~km})$ es necesario un tiempo de posicionamiento de 60 minutos empleando un receptor GPS de doble frecuencia; no obstante, también precisa que es posible para una línea geodésica aplicar los mismos parámetros para receptores GPS de una sola frecuencia en distancias menores a $20 \mathrm{~km}$. Evidentemente las precisiones alcanzadas con los receptores GPS de bajo costo son altas en comparación a un receptor de una frecuencia; sin embargo, acorde con Realini y Reguzzoni (2013), es posible alcanzar una precisión equiparable a un receptor GPS de doble frecuencia a través de una metodología y estrategias de procesado pensando en el uso de software científico como el caso de RTKLIB, GAMIT/GLOBK, GLAB, entre otros.

Otro aspecto fundamental que mejoraría el posicionamiento en la componente vertical y horizontal es el buen manejo de los saltos de ciclo, ya que comparados con los receptores de alta precisión (doble frecuencia o una frecuencia geodésicos) los receptores GPS de bajo costo están sujetos a fuentes de error como el efecto multitrayectoria, variación del centro de fase y ruidos de la baja calidad de los componentes electrónicos que son involucrados. Según lo expuesto por Herrera et al. (2016), es posible implementar este tipo de receptores para el posicionamiento y mapeo, pero considerando los efectos descritos es posible alcanzar un posicionamiento preciso.

\section{Conclusiones}

Dado el incremento de los receptores GPS de bajo costo en la ingeniería, es posible utilizar estos equipos para trabajos topográficos considerando una cuidadosa metodología de procesamiento de las observaciones y además de usar parámetros específicos para la zona de estudio. Evidentemente, se encuentran en una fase de crecimiento para ser evaluados bajo los estándares para su implementación en las redes geodésicas o bien para estudios de otra índole. Una vez evaluado cada receptor GPS de bajo costo, se encuentra que el receptor NVS08CSM tuvo una mejor respuesta en las observaciones en ambos software. Al estar sujeto a comparación, considerando como la posición real a la que se calcula mediante el receptor GPS del fabricante Leica, se observó que el posicionamiento mantuvo una diferencia de $3 \mathrm{~cm}$, lo cual es factible para trabajos geodésicos (considerando que está dentro del margen del receptor GPS de una frecuencia); sin embargo, dadas las soluciones obtenidas para la cuestión vertical, son recomendables estos equipos para trabajos topográficos en los cuales sea posible utilizar alturas ortométricas o bien para trabajos pertinentes a los sistemas de información cartográfica donde sean necesarios trabajos de mapeo. 


\section{Análisis Prospectivo}

Hoy en día gracias al desarrollo tecnológico es posible utilizar receptores geodésicos GNSS de precisiones milimétricas; no obstante, no son accesibles en cuanto a precio de adquisición se refiere. Por otro lado, existen equipos de bajo costo que gracias a su reducido tamaño, peso y su alta accesibilidad los hace aptos para un mayor número aplicaciones geodésicas y topográficas, así como para otras actividades donde sea necesario el geoposicionamiento. Con los instrumentos (receptores de bajo costo) es posible innovar en áreas donde sea requerido el posicionamiento satelital, por ejemplo en aplicaciones como robótica, servicios de ayuda y rescate, levantamientos topográficos, catastrales, entre otras. Enfatizando en el ámbito de la construcción, poder alcanzar precisiones en el orden de centímetros al igual que un receptor geodésico de una frecuencia permitirá la implementación de los receptores de bajo costo para el cumplimiento de normas constructivas y estándares de calidad reduciendo de este modo los costos en las obras.

\section{REFERENCIAS}

Adafruit. (2017). Raspberry Pi. Disponible en https://www.adafruit.com

Barragan-Currea, J. (2015). Determinación, corrección y ajuste de coordenadas GPS para las fases de vuelo, aproximación y aterrizaje. Desarrollo de un sistema GBAS para el aeropuerto de Nemocón (Cundinamarca). Revista de Topográfia Azimut, 6(6), 1-14.

Benedetti, E., Dermanis, A., \& Crespi, M. (2017). On the feasibility to integrate low-cost MEMS accelerometers and GNSS receivers. Advances in Space Research, 59(11), 2764-2778. https://doi.org/10.1016/j. asr.2017.02.005

Benoit, L., Briole, P., Martin, O., Thom, C., Malet, J., \& Ulrich, P. (2015). Monitoring landslide displacements with the Geocube wireless network of low-cost GPS. Engineering Geology, 195, 111-121. https://dx.doi. org/10.1016/j.enggeo.2015.05.020

Bhatti, J., \& Humphreys, T. (2017). Hostile control of ships via false GPS signals: Demonstration and Detection. Navigation, 64(1), 51-66. https://doi.org/10.1002/navi.183

Biagi, L., Grec, F., Negretti, M., \& Visconti, M. (2015). Local monitoring by low cost devices and free and open sources softwares (pp. 431-436). FOSS4G Europe 2015.

Cabral, J., Mendes, V., Figueiredo, P., Silveira, A., Pagarete, J., Ribeiro, A. \& Ressurreição, R. (2017). Active tectonics in Southern Portugal (SW Iberia) inferred from GPS data. Implications on the regional geodynamics. Journal of Geodynamics, 112, 1-11. https://doi.org/10.1016/j. jog.2017.10.002

Calina, A., Jenica, C., \& Alin, C. (2015). Study on building of planimetric network stakeout for a commercial space using combined technology GPS-Total Station. Scientific Papers-Series E-Land Reclamation Earth Observation \& Surveying Environmental Engineering, 4, 127-134.

Chen, X., Cui, T., Fu, J., Peng, J., \& Shan, J. (2016). Trend-residual dual modeling for detection of outliers in low-cost GPS trajectories. Sensors, 16(12), 1-16. https://doi.org/10.3390/s16122036

Díaz-Hernández, C. (2001). Redes de la base geodésica planimétrica de apoyo, en Manual de geodesia aplicada, principios y métodos (p. 25). Universidad Autónoma de Sinaloa.

Estey, L., \& Wier, S. (2014). Teqc tutorial: Basics of Teqc use and Teqc products. Boulder, Colorado: UNAVCO. Disponible en http://www.unavco.org 
Ghilani, C. (2010). Measures of central tendency. In Adjustment computations: Spatial data analysis (5th ed., pp. 17-20). Wiley Sons, Inc.

Guerova, G., Jones, J., Dousa, J., Dick, G., de Haan, S., \& Pottiaux, E. Bender, M. (2016). Review of the state-ofthe-art and future prospects of the ground-based GNSS meteorology in Europe. Atmospheric Measurement Techniques Discussions, 9(11), 1-34. https://doi.org/10.5194/amt-2016-125

Herrera, A. M., Suhandri, H. F., Realini, E., Reguzzoni, M., \& de Lacy, M. C. (2016). goGPS: Open-source MATLAB software. GPS solutions, 20(3), 595-603.

Hofmann-Wellenhof, B., Lichtenegger, H., \& Wasle, E. (2008). Differential positioning. In GNSS globalnavigation satellite sistem (pp. 169-172). Springer Wien New York.

Huang, S., Zhang, Z., He, J., \& Ke, T. (2016). Image Network Generation of Uncalibrated Uav Images With Low-Cost GPS Data. ISPRS-International archives of the photogrammetry, remote sensing and spatial information sciences, 41, 31-37. https://Id:10.5194/isprsarchives-xli-b3-31-2016

IIEG. (2011). Lineamientos Técnicos para la Red Geodésica Estatal y Especificaciones Relativas al uso de Técnicas de Posicionamiento por Satélite (pp. 1-43). Jalisco: Instituto de Información, Estadística y Geografía. Disponible en https://iieg.gob.mx/contenido/GeografiaMedioAmbiente/RedGeodesicaEstatal

INEGI. (1998). Normas técnicas para levantamientos geodésicos. Instituto Nacional de Estadística, Geografía e Informática. Disponible en http://www.inegi.org.mx/geo/contenidos/normastecnicas/default.aspx

INEGI. (2010). Norma técnica sobre estándares de exactitud posicional. Instituto Nacional de Estadística, Geografía e Informática. Disponible enhttp://www.inegi.org.mx/geo/contenidos/normastecnicas/default.aspx

INEGI. (2017). Red geodésica nacional activa. Instituto Nacional de Estadística, Geografía e Informática Disponible en http://www.inegi.org. $\mathrm{mx} /$ geo/contenidos/geodesia/rgna.aspx $\mathrm{p}=22 \& \mathrm{dv}=\mathrm{c} 1$

Keskin, M., Sekerli, Y., \& Kahraman, S. (2017). Performance of two low-cost GPS receivers for ground speed measurement under varying speed conditions. Precision Agriculture, 18(2), 264-277. https://doi. org/10.1007/s11119-016-9453-x

Klobuchar, J. (1987). Ionospheric time-delay algorithm for single-frequency GPS users. IEEE Transactions On Aerospace And Electronic Systems, AES, 23(3), 325-331. https://doi.org/10.1109/taes.1987.310829

Korpilo, S., Virtanen, T., \& Lehvävirta, S. (2017). Smartphone GPS tracking-Inexpensive and efficient data collection on recreational movement. Landscape And Urban Planning, 157, 608-617. https://dx.doi. org10.1016/j.landurbplan.2016.08.005

Krenn, P., Titze, S., Oja, P., Jones, A., \& Ogilvie, D. (2011). Use of Global Positioning Systems to study physical activity and the environment. American Journal of Preventive Medicine, 41(5), 508-515. https://doi. org10.1016/j.amepre.2011.06.046

Leica Geosystems AG. (2006). Leica SR20 (pp. 1-4). Heerbrugg, Suiza: Leica Geosystems AG. Disponible en http://w3.Leica-geosystems.com/downloads123/zz/gpsgis/sr20/brochures/SR20 Brochure_es.pdf

Leica Geosystems AG. (2017). Leica Geo Office, online help (p.1021). Switzeland: Leica Geosystems AG.

Leick, A., Rapoport, L., \& Tatarnikov, D. (2015). Satellite systems. In GPS Satellite surveying (4th ed., p. 226). John Wiley \& Sons, Inc.

Leonard, J., \& Bahr, A. (2016). Autonomous underwater vehicle navigation. In Springer Handbook of Ocean Engineering (pp. 341-358). Springer International Publishing.

Liu, J., Wan, J., Wang, Q., Deng, P., Zhou, K., \& Qiao, Y. (2016). A survey on position-based routing for vehicular ad hoc networks. Telecommunication Systems, 62(1), 15-30. https://doi.org/10.1007/s11235015-9979-7 
Matias, B., Oliveira, H., Almeira, J., Dias, A., Ferreira, H., Martins, A., \& Silva, E. (2015). High-accuracy low-cost RTK-GPS for an unmannned surface vehicle. In OCEANS 2015-Genova (pp. 1-4). IEEE.

Monjardin, S., Pacheco, C., Plata, W., Corrales, G., Romero, R., \& Beltran, J. (2016). Processing and deep analysis of hot spot areas of deforestation using remote sensing and geographic information system techniques. Case study: State Sinaloa, México. Scientific Research Publishing, 295-304.

Negrel, J., Gerland, S., Doulgeris, A., Lauknes, T., \& Rouyet, L. (2017). On the potential of hand-held GPS tracking of fjord ice features for remote-sensing validation. Annals of Glaciology, 59,73-180. https://doi. org/10.1017/aog.2017.35

Realini, E., \& Reguzzoni, M. (2013). GoGPS: Open source software for enhancing the accuracy of low-cost receivers by single-frequency relative kinematic positioning. Measurement Science and technology, 24(11), 115010 .

Ren, X., Zhang, X., Xie, W., Zhang, K., Yuan, Y., \& Li, X. (2016). Global ionospheric modelling using multiGNSS: BeiDou, Galileo, GLONASS and GPS. Scientific Reports, 6(1). https://doi.org/10.1038/srep33499

Rodríguez-Pérez, J., Álvarez, M., \& Sanz-Ablanedo, E. (2007). Assessment of low-cost GPS receiver accuracy and precision in forest environments. Journal of Surveying Engineering, 133(4), 159-167. https://doi. org/10.1061/(asce)0733-9453(2007)133:4(159)

Saastamoinen, J. (1972). Atmospheric correction for the troposphere and stratosphere in radio ranging satellites. Geophysical Monograph Series, 15(4), 247-251.https://doi.org/10.1029/GM015p0247

Samad, A., Waheed Mir, A., Hamid Chaudry, M., Hamid, Q., Samad, N., \& Haris, M. (2016). Establishment of geodetic baseline. Science International, 28(1).

Schwieger, V. (2009). High-Sensitivity GPS-an availability, reliability and accuracy test. Bulletin Des Sciences Géographiques, 23. Disponible en http://www.webreview.dz/spip.php?article1649

Takasu, T., \& Yasuda, A. (2009). Development of the low-cost RTK-GPS receiver with an open source program package RTKLIB. International Symposium On GPS/GNSS, 1-6.

Takasu, T., \& Yasuda, A. (2013). RTKLIB ver. 2.4.2 Manual (pp. 1-181). Disponible en http://www.rtklib. com/rtklib.htm

Tallysman TW4721. (2017). Disponible en http://www.tallysman.com/index.php/gnss/products/antennas-gpsbeidougalileoglonass/tw4721/

Tomaštík, J., Tomaštík, J., Saloň, Š., \& Piroh, R. (2017). Horizontal accuracy and applicability of smartphone GNSS positioning in forests. Forestry, 90(2), 187-198. https://doi.org/10.1093/forestry/cpw031

Tsakiri, M., Sioulis, A., \& Piniotis, G. (2016). The use of low-cost, single-frequency GNSS receivers in mapping surveys. Survey Review, 50(358), 46-56. https://doi.org/10.1080/00396265.2016.1222344

Tsakiri, M., Sioulis, A., \& Piniotis, G. (2017). Compliance of low-cost, single-frequency GNSS receivers to standards consistent with ISO for control surveying. International Journal of Metrology and Quality Engineering, 8, 11. https://doi.org/10.1051/ijmqe/2017006

Van Digglen, F. (2009). Signal strengths in practice and attenuation through different materials. In $A$-GPS: Assisted GPS, GNSS, and SBAS (pp. 215-216).

Zhang, S., Teizer, J., Pradhananga, N., \& Eastman, C. (2015). Workforce location tracking to model, visualize and analyze workspace requirements in building information models for construction safety planning. Automation in Construction, 60, 74-86. https://doi.org/10.1016/j.autcon.2015.09.009

CC BY-NC-ND 